\title{
$\operatorname{Samml\mathfrak {mg}}$
}

$\mathfrak{D} \mathfrak{e} \mathfrak{x}$

fïr bie Röniglich Preupifatse Mheill= Proving

feit bem Sahre 1813

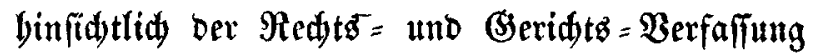

ergangenen

\section{(otejeke, Beroromumgen, Mintifterinl $=$ :Rejcripte $\mathfrak{x}$.}

\author{
פ̇raugegeben \\ im
}

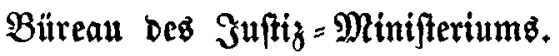

$B \mathfrak{B} \mathfrak{b} \mathfrak{l}$ fter $\mathfrak{B} \mathfrak{a} \mathfrak{b}$,

welder Die Sagre 1858, 1859, 1860, 1861, 1862,

1863 und 1864 entbält.

\section{Serlin,}

Druff unb Berlag von Beorg $\Re$ eimer.

1865. 
